\title{
Nutrition and health development - lessons from Kerala
}

\author{
BY C. R. SOMAN \\ Medical College, Trivandrum, India
}

The state of Kerala is located in the southern tip of India. It is a narrow strip of land flanked by the Arabian sea on the west and Western Ghats mountain ranges on the east. With over 29 million people living in an area of $38863 \mathrm{~km}^{2}$. Kerala's density of population stands at $747 / \mathrm{km}^{2}$, second only to Bangladesh. The annual rainfall spread over two monsoon seasons is a little over $2400 \mathrm{~mm}$ and the temperature ranges from $27^{\circ}$ to $32^{\circ}$. The climate is semi-tropical, hot and moist.

Although only one of the twenty-five states of India, Kerala has the attention of the world for its unique achievements in health. The state's achievement has been variously heralded as being the result of great stress on sound development (Nag, 1983), greater social justice (Ratcliffe, 1978) or a combination of greater stress on education and improved health delivery system (Nair, 1974). Table 1 presents a summary of the salient features of Kerala in comparison with the United Kingdom.

Table 1. Basic indicators - Kerala, United Kingdom and India*

\begin{tabular}{lccc}
\hline Indicator & Kerala & United Kingdom & India \\
Life expectancy & 70 & 76 & 59 \\
Adult illiteracy & $<5$ & $<5$ & 57 \\
GNP (US dollar) & 180 & 14610 & 200 \\
IMR & 20 & 9 & 95 \\
Energy supply: kcal & $<2000$ & 3252 & 2104 \\
& $8 \cdot 4$ & $13 \cdot 6$ & $8 \cdot 8$ \\
Institutional births (\%) & 92 & 98 & 39 \\
Birth rate & 18 & 14 & 31 \\
CDR & $6 \cdot 2$ & 11 & 11 \\
TFR & 2 & 1.9 & $4 \cdot 1$ \\
\hline
\end{tabular}

* Values for UK and India are reproduced from World Development Report, 1990. Values for Kerala are compiled from official publications.

GNP, gross national product; IMR, infant mortality rate (/1000); CDR, crude death rate (/1000); TFR, total fertility rate.

These figures reflect the tremendous strides the state has made in many spheres of health. The gains are all the more impressive since the income of the state falls below the national average. In the present paper the status of health and nutrition in Kerala will be examined and related to the state's developmental experience.

\section{HEALTH SITUATION IN KERALA}

Although numerous indicators are available to measure the health status of a population, the present discussion is restricted to indicators of mortality, fertility, morbidity, and disability. It has been mentioned already that infant mortality rate (IMR) in Kerala has declined to $20 / 1000$. At the beginning of the century, the IMR of the state was 


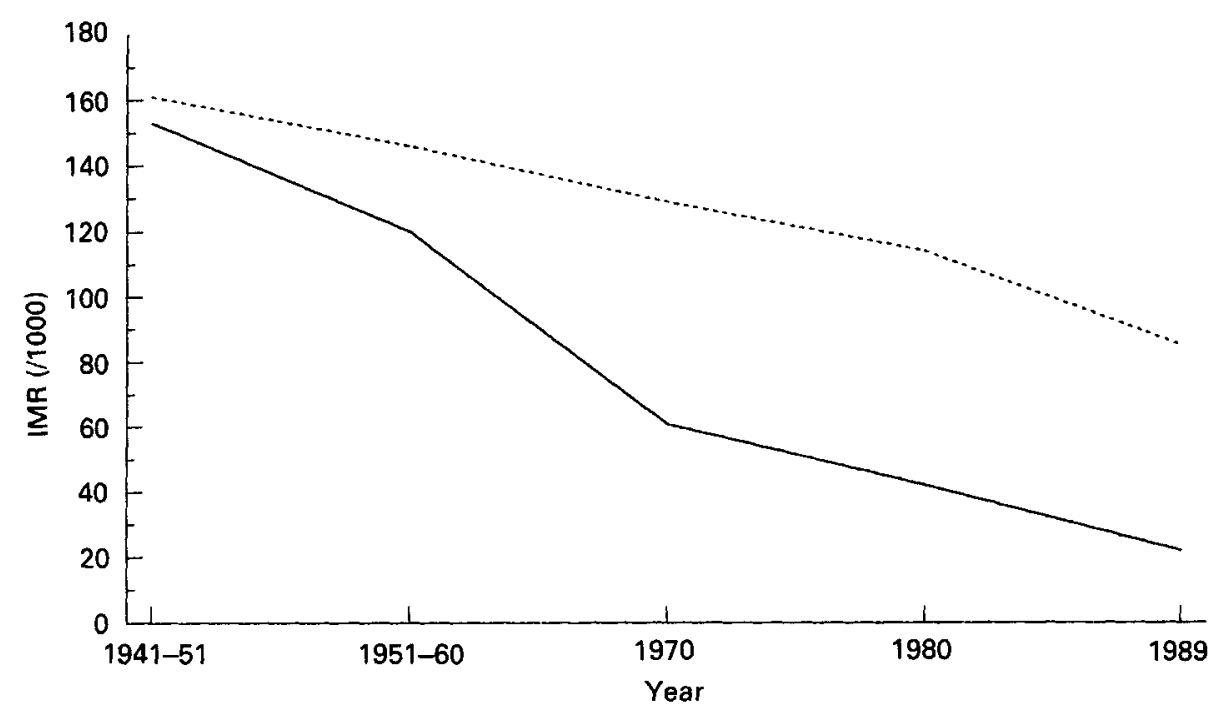

Fig. 1. Fall in infant mortality (IMR; /1000) in India (- . ) and Kerala (_-) between 1951 and 1990.

very high and did not differ much from the all India figures $(242 v .278)$. While in Kerala the IMR declined steadily throughout this century, to the present level of $20 / 1000$, the rate of decline was much smaller for the country as a whole, having declined only to 95/1000 by 1989 (Fig. 1). Another feature of Kerala's mortality profile is the very small difference between rural and urban areas. In 1989, the rural IMR stood at $23 / 1000$ compared with $15 / 1000$ for urban IMR with a state average of $22 / 1000$ live births.

The crude death rate (CDR) which remained at $17 / 1000$ has also declined rapidly to the present level of $6 \cdot 2 / 1000$ population, and during the last many years, the urban and the rural rates have remained virtually identical. The CDR, which remains lower than those of many developed countries, partly reflects the age profile weighted towards the young. It is estimated that the proportion of children under 14 years constitutes just over $30 \%$ of the population, while the corresponding value for the United Kingdom is $19 \%$. Calculations based on age-specific mortality rates indicate that the CDR for Kerala would rise to $15 / 1000$ if its population structure were adjusted to that of the United Kingdom. A unique feature of Kerala's population profile is that, unlike in the rest of India, the gender ratio favours women (1040:1000). Age-specific mortality rates for the sexes clearly indicate that, except for the age-group 15-19 years, male mortality exceeds female mortality, a feature consistently observed during recent decades.

Morbidity indicators. In the context of such a sharp decline in mortality, one would expect evidence for a parallel decline in morbidity and significant changes in the profile of diseases. Surprisingly, the available evidence does not support such an assumption. It should, however, be noted that information on morbidity is far more difficult to collect and very often the data are of dubious reliability. Cause of death statistics from the community are collected by persons not trained medically and, therefore, of little value. Annual statistics of the health services departments furnish information of the number of patients seeking medical admissions and also on the diseases for which they are treated. Data from the medical college hospitals provide some clue to the pattern and burden of 
Table 2. Proportion of children treated for selected communicable diseases at SAT Hospital, Trivandrum 1964-84

\begin{tabular}{lrccc}
\hline Disease & $1964-67$ & $1967-70$ & $1973-76$ & $1980-84$ \\
\hline Respiratory tuberculosis & 17 & 21 & 20 & $25^{*}$ \\
Non-respiratory tuberculosis & 18 & 18 & 15 & - \\
Diphtheria & 27 & 31 & 22 & 3 \\
Whooping cough & 25 & 30 & 29 & 3 \\
Tetanus & 1 & 1 & 2 & 21 \\
Measles & 36 & 50 & 23 & 20 \\
Acute poliomyelitis & 11 & 7 & 15 & 201 \\
Gastroenteritis & 198 & 201 & 210 & 21 \\
Dysentery & 64 & 37 & 27 & 0 \\
Cholera & 0 & 0 & 0 & 31 \\
Infective hepatitis & 39 & 37 & 24 & 5 \\
Enteric fever & 30 & 30 & 21 & 351 \\
Total & 466 & 463 & 408 & \\
\hline
\end{tabular}

* Includes non-respiratory tuberculosis also.

common illness in the community. The information available from the Trivandrum Medical College, collected for the last 30 years is shown in Table 2.

It is quite clear that over the years, the mortality profile has not changed significantly and that infections and parasitic diseases contribute a significant share of the total illness in the population. This impression is further corroborated by studies on childhood illness. Preschool children in the urban environment suffer on average more than $100 \mathrm{~d}$ of illness and the average number of disease-free weeks was less than 26 for the whole year. Fever, respiratory diseases, diarrhoea and skin disorders contribute to the bulk of childhood diseases (United Nations Children's Fund, 1991a). Field studies indicate that worm infestations are widely prevalent in the rural areas. Nearly $70-80 \%$ of children suffer from worm infestations. Over the last 50 years, there has been a drastic reduction in the prevalence of hookworm infestations but the prevalence of round worm and whip worm infestations has not recorded significant reductions (Institute of Management in Government, 1989). The changing demographic profile and rapid alterations in the life-style of a section of the population have brought about the emergence of hypertension, ischaemic heart disease, cerebrovascular diseases and cancers as major diseases (Panikar \& Soman, 1984).

Well-designed population-based morbidity surveys have not been carried out recently to enable countrywide comparisons between different Indian States. The one available report (National Sample Survey Organization, 1983) indicates that, paradoxically, the prevalence of morbidities were the highest in Kerala, even though the duration of the morbidities were generally lower. Morbidity information collected from the population is coloured by many factors, most important of which is the perceptional factor. It is to be expected that in communities with a high level of literacy, there is higher awareness of illness and reported morbidity will be higher.

A recent study covering rural Kerala has again brought into sharp focus the prevalence of significant levels of morbidity in the community (Kannan et al. 1991). The survey reveals that the average morbidity was $206 \cdot 39 / 1000$ persons over a 2 -week period. The 
corresponding figures were only $71 \cdot 29 / 1000$ in 1973 . The prevalence of chronic morbidity was also quite high, the figure being $138 \cdot 02 / 1000$ persons. The illness pattern showed significant differences between the social classes. The poorer classes suffered more from diarrhoea and fever, while the higher socio-economic classes suffered more from the newer life-style diseases like ischaemic heart disease, hypertension and diabetes. Sex differences in morbidity were minimal.

The shift in the spectrum of illness based on socio-economic status has also been corroborated by other observations (Panikar \& Soman, 1984). The picture which emerges is one of high prevalence of morbidity, despite sharp declines in mortality during the last few decades. The annual reports for the year 1988-89 (Government of Kerala, 1991) of the Health Service Department reveals the picture fairly dramatically. During the year (1988-89) there were 786632 cases of diarrhoeal diseases, 55362 cases of tuberculosis and 23156 cases of measles, certainly indicating high morbidity load for a state with low mortality. Many communicable diseases like poliomyelitis, pertussis and viral hepatitis still appear in large numbers annually.

\section{FERTILITY DECLINE}

Kerala's unique experience in fertility transition has been the subject of much attention (Zacharia, 1984; Mari Bhat \& Irudaya Rajan, 1990). In 1990, the overall birth rate was estimated to be $18 / 1000$ and in many populous districts it has declined to levels as low as $12 / 1000$. Over the last 33 years, the birth rate has fallen from 40 to $18 / 1000$, by no means a small decline! A small but significant part of the decline was related to a steady upward shift in the age of marriage. The mean age of marriage for girls in 1990 was 22.8 years compared with 18 years for the rest of the country. Widespread adoption of contraceptive practices has also had an impact on the birth rate, the choice of the people being female sterilization.

An interesting aspect of the fertility decline is that the fall in birth rate is not uniformly experienced throughout the state. The birth rate has fallen to replacement fertility levels in most of central and southern Kerala while it is higher in northern Kerala. This geographical difference is best explained in terms of sharp differences in the educational level of women in these areas. Studies reveal that the birth rate is fairly equal in south and north Kerala among the main religions, for comparable levels of education. However, there is a sharp increase in birth rate in districts where female literacy remains relatively low (Census of India, 1991). The relationship between female education and population growth is elegantly demonstrated by the Kerala experience (Fig. 2). The most interesting feature is that such dramatic declines have occurred in the span of just over 30 years, a phenomenon without many parallels among low-income countries (Krishnan, 1991). Sri Lanka is perhaps the only exception.

\section{NUTRITIONAL LEVELS OF THE PEOPLE}

Studies on the nutritional status of the people of Kerala have been carried out occasionally since the early 1940s. These studies, however, were restricted to selected groups of individuals in isolated groups and cannot be considered representative. However, an analysis of the available data indicates that both dietary intake and anthropometric measurements fell far below the expected levels during the 1940s, 1950s 


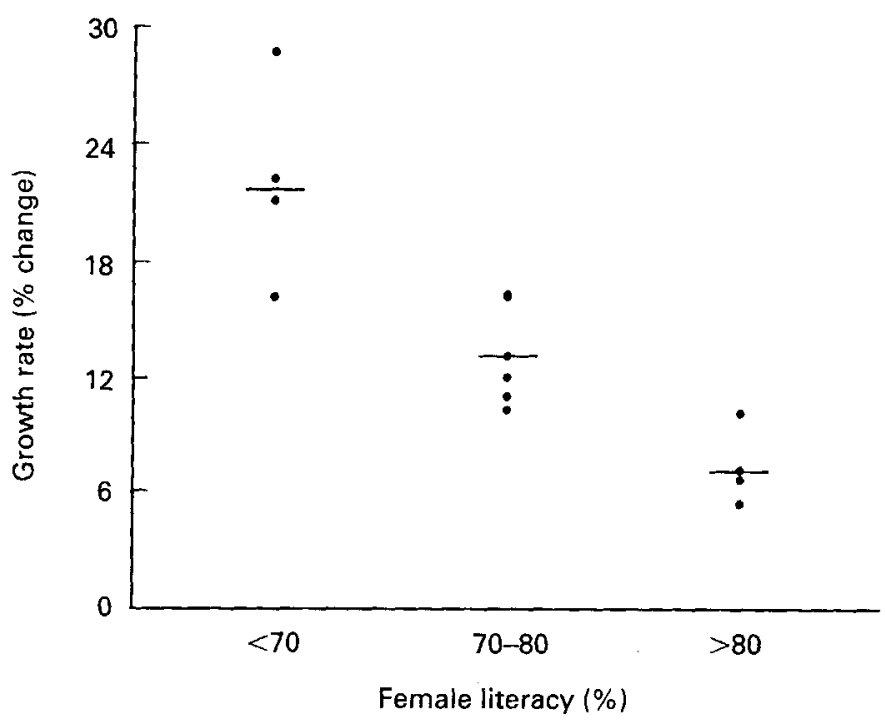

Fig. 2. Population growth (\% change over 10 years) and level of female literacy in Kerala in 1991. Each point represents one district.

and the 1960s (Panikar \& Soman, 1984). The mean height and weight of children throughout this period fell below three standard deviation levels of the (US) National Center for Health Statistics (1976; NCHS) standards, even though a small but steady increase in height and weight could be noticed over the years.

Representative nutritional studies covering both rural and urban areas of many Indian states including Kerala are being carried out by the National Nutrition Monitoring Bureau (NNMB) of the Indian Council of Medical Research. The reports are regularly published. The investigations include anthropometric and clinical examination of representative members of the population and estimating food consumption at the household level. In addition, individual consumption is estimated using the $24 \mathrm{~h}$ recall method. The NNMB has been regularly publishing its reports, the most recent being the one for the year 1990, in which the results obtained from the studies of 1975-79 are compared with those of 1989-90. Data for Kerala are provided along with that of other Indian states (National Nutrition Monitoring Bureau, 1990).

\section{FOOD CONSUMPTION DATA}

The NNMB data clearly demonstrate that consumption of most nutrients falls below the recommended dietary intake (Table 3 ). It may be recalled that the values are given on a per consumption unit basis. Consumption values for specific categories have not been provided in the report for 1990 .

The data also suggest that the intake registered a modest increase over values for 1975-79. More interestingly the consumption of nutrients in the state remains the second lowest among the eight major states studied in 1990, while it was the lowest in 1975-79 (National Nutrition Monitoring Bureau, 1980). Food intake studies carried out on pregnant and lactating women also reveal the same trends. That Kerala ranks lowest in 
Table 3. Average consumption of nutrients - Kerala, 1990

\begin{tabular}{|c|c|c|}
\hline Nutrient & Consumption $(/ \mathrm{CU})$ & $\mathrm{RDI}^{*}$ \\
\hline Energy (MJ) & 8.95 & 9.83 \\
\hline Protein (g) & $52 \cdot 9$ & $60 \cdot 0$ \\
\hline Calcium (mg) & 608 & 400 \\
\hline Iron (mg) & $22 \cdot 0$ & $28 \cdot 0$ \\
\hline Vitamin A (mg) & 297 & 600 \\
\hline Vitamin C (mg) & $47 \cdot 0$ & 40 \\
\hline Thiamin (mg) & 0.72 & $1 \cdot 2$ \\
\hline Riboflavin (mg) & 0.74 & $1 \cdot 4$ \\
\hline Niacin (mg) & $11 \cdot 80$ & $16 \cdot 0$ \\
\hline
\end{tabular}

$\mathrm{CU}$, consumption unit; RDI, recommended daily intake.

* Indian Council of Medical Research (1990).

Table 4. Prevalence of malnutrition (percentage of children under each nutritional grade, in relation to (US) National Center for Health Statistics (1976) standards) among preschool children (girls) in selected states -1990

\begin{tabular}{lcccc}
\hline State & Normal & Mild & Moderate & Severe \\
\hline Kerala & 14.5 & 38.9 & 34.4 & 2.2 \\
Tamilnadu & 7.0 & 38.5 & 49.7 & 4.8 \\
Karnataka & 2.7 & 33.6 & 53.4 & 10.4 \\
Andhrapradesh & 5.8 & 32.1 & 52.7 & 9.4 \\
\hline
\end{tabular}

food intake has also been confirmed by surveys of the National Sample Survey Organization $(1980,1983)$.

One would naturally expect such low levels of nutrient consumption to be associated with severe growth retardation and the prevalence of clinical nutritional disorders. Paradoxically, the nutritional picture is not so bleak. Kerala has the highest proportion of normally nourished and the lowest proportion of severely undernourished children under 5 years of age (Table 4). The picture was the same even during the 1970s (National Nutrition Monitoring Bureau, 1980). Kwashiorkor has virtually disappeared and the prevalence of marasmus has also declined dramatically over the years. The height and weight of children also were slightly better in Kerala. However, the mean values for height and weight correspond only with the third centile of the NCHS values (Figs 3 and 4).

Although the intake of most micronutrients also falls below the recommended levels, clinical examination suggests that the picture is far better than in other Indian states. Recent studies carried out by the author on haemoglobin status of poor rural communities indicate that the mean haemoglobin level was $123 \mathrm{~g} / \mathrm{l}$ among preschool children and that the percentage of children with levels below $110 \mathrm{~g} / \mathrm{l}$ was only 20 , a significant improvement over the picture in the mid 1970 s, when over $82 \%$ of children had haemoglobin levels below $110 \mathrm{~g} / 1$ (Panikar \& Soman, 1984). 


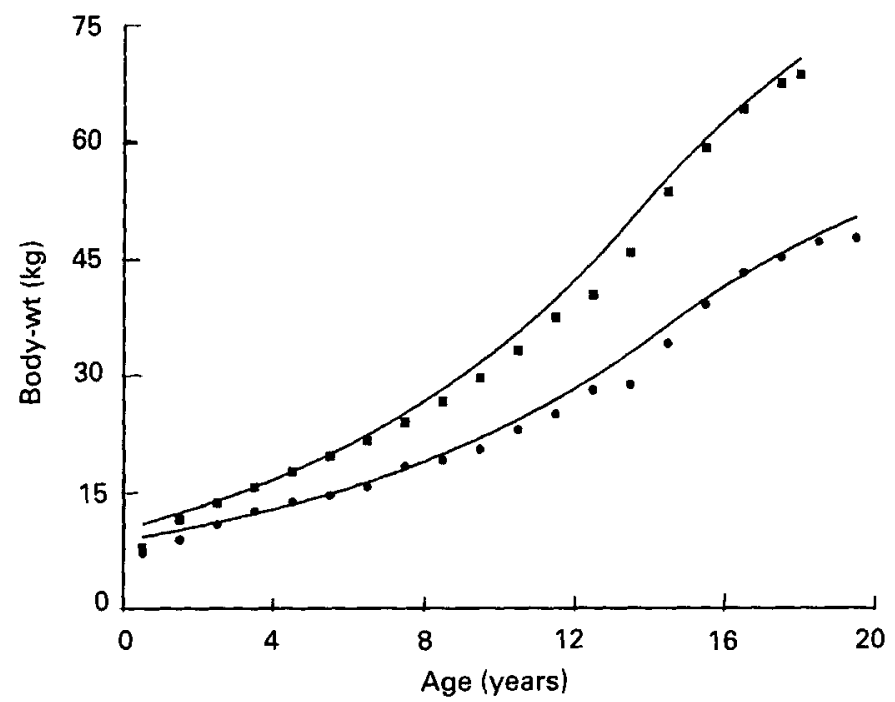

Fig. 3. Body-weights (kg) of boys in Kerala in 1990. (a) (US) National Center for Health Statistics median and $(\bullet)$ Kerala mean.

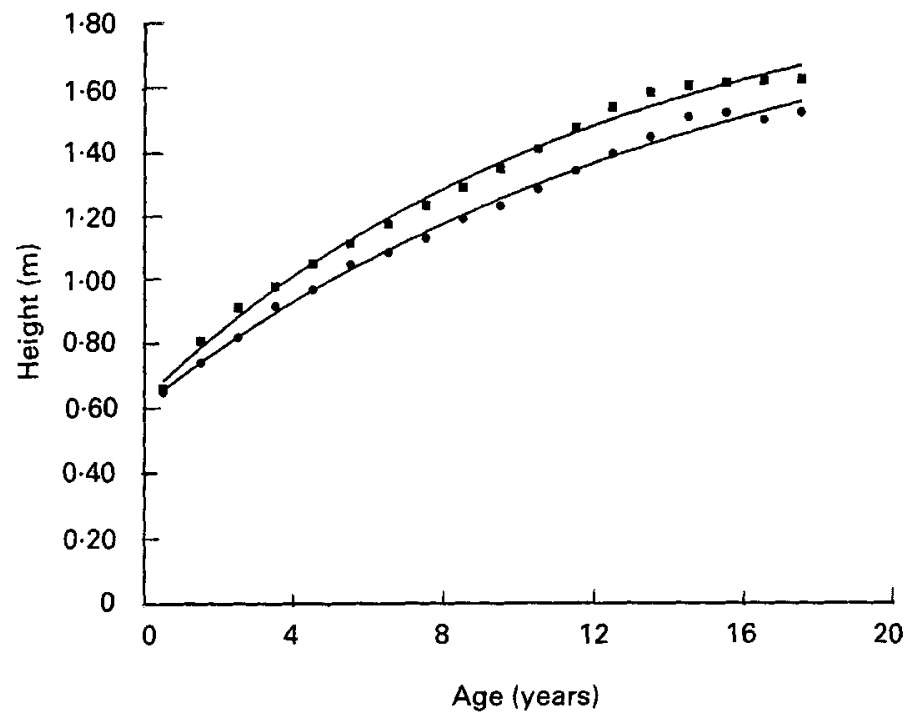

Fig. 4. Heights (m) of girls in Kerala in 1990. (ם) (US) National Center for Health Statistics median and (O) Kerala mean.

\section{BIRTH WEIGHT TRENDS}

Review of the birth weight of children over the last 30 years from the teaching hospital indicates that the birth weight steadily increased during the 1960 s and 1970 s but has started declining since the mid 1980s. Low-birth-weight babies $(<2.5 \mathrm{~kg})$ comprised $21 \%$ of all births in 1989 (Lulu Netto, 1989). In the absence of community-based observations, 
Table 5. Distribution of height (percentage in each height category) of mothers 1971 and 1987

\begin{tabular}{ccc}
\hline Height $(\mathrm{m})$ & 1971 & 1987 \\
\hline$<1.45$ & 20.0 & 22.5 \\
$1.46-1.50$ & 27.6 & 24.2 \\
$1.51-1.55$ & 40.8 & 25.0 \\
$1.56-1.60$ & 7.6 & 19.0 \\
$>1.60$ & 4.0 & 8.6 \\
\hline
\end{tabular}

it would be premature to conclude that the decline in the birth weight augurs a deteriorating nutritional situation. However, figures from the four medical colleges located in the different areas of the state suggest that the birth weight situation is far from encouraging, since the mean birth weight did not exceed $2810 \mathrm{~g}$ in any region and low-birth-weight babies constituied over $20 \%$ of total births in all regions of the state.

As birth weight is much influenced by the nutritional status of the mothers, in addition to the nature and quality of antenatal services and diet during pregnancy, we examined the available information on maternal height and weight in the collegiate hospitals during the 1970s and the late 1980s. Surprisingly, there was very little shift in the overall nutritional status of pregnant women admitted for delivery during the two periods (Table 5 ). The average haemoglobin levels of the mothers, however, registered improvement during the intervening period. As already discussed, dietary intake of iron remains below recommended daily intakes among all sections in the state and improvement in haemoglobin can only be attributed to extensive utilization of antenatal services in which Fe supplementation is an essential component.

\section{DISCUSSION}

What, then, are the lessons from the Kerala experience? How did the state, with its population subsisting on low nutritional intake manage to achieve a dramatic fall in mortality and fertility? How can one reconcile the low mortality with high levels of morbidity, particularly infectious diseases? One has to explore Kerala's developmental experience in greater detail to seek the answers.

It was mentioned earlier that the state has achieved high levels of literacy. In fact, the whole state was declared to have achieved total literacy in 1990, the successful fruition of efforts dating back to the previous century. Kerala's literacy level in 1960 was already higher than that which could be achieved by the rest of India in 1990. School education was given top priority even before the country attained independence and rapid expansion in educational facilities followed the formation of Kerala state in 1956. School enrolment in the 6-11 years age-group became nearly $100 \%$ by the 1980 s. In the early part of the century, the emphasis was on primary education and later greater stress was laid on secondary and college education. A unique feature of the educational system is the high enrolment of girls in schools. Although in lower socio-economic classes, the percentage of girls attending schools is only about $90 \%$ that of the boys, the pattern shifts in favour of girls in college education both at the pre-degree and post-graduate courses (Government of Kerala, 1991). 


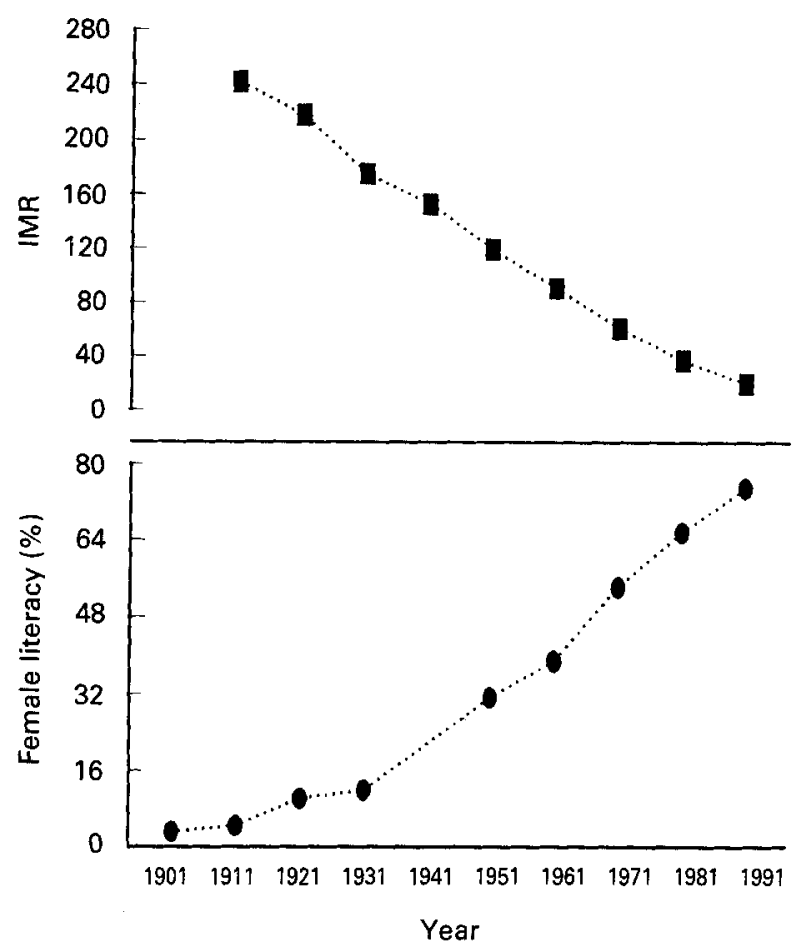

Fig. 5. Infant mortality (IMR; /1000) and female literacy (\%) in Kerala between 1901 and 1991.

Female literacy has been considered a very important determining factor for effecting declines in mortality (Caldwell, 1986). Examination of the data reveals the striking relationship between the rise in female literacy and fall in infant mortality in Kerala (Fig. 5). There is no doubt, therefore, that the gains in mortality reduction achieved are the return for the investment on education, particularly female education. In $1981,71 \%$ of women aged 15 years or above were literate in Kerala compared with $26 \%$ for the country as a whole. Education is believed to exert a powerful impact on mortality because it makes mothers less fatalistic about illness, more concerned and determined to take care of their children when they fall sick and more articulate in demanding health care. The state had already created by the 1950 s a critical core of educated women in most regions which in turn would have created a greater demand on health care facilities. The political system had no other option but to respond by providing more institutions for health care and delivery. The demonstration effect of modern medical care would have even percolated to the less-educated masses.

An examination of the growth of health services in Kerala reveals the rapid expansion and spread of health care facilities. Initially, the health care sector in modern medicine was the almost exclusive domain of the Government. The first medical college to train students in modern medicine was formed in 1956 and since then there has been a steady increase in the output of doctors, the present annual out-turn being estimated at 1000 per year. Over 15000 doctors have been added to the registers in the last 30 years, of whom not more than 4500 could be absorbed into Government service. Most of the rest had to 
seek non-governmental jobs. Thus, despite the phenomenal growth in the Government health care system, both in terms of institutions and manpower, the non-governmental system has grown at a faster pace. At present, the private sector commands more institutions, more beds, and more doctors. With the demand for better health care and more facilities, doctors migrated even to rural areas and nowhere in India are villages better served than in the rural areas of Kerala. The average catchment area of a health institution is only $5 \mathrm{~km}^{2}$ in rural Kerala while the figure is ten times as large in many parts of India. The traditional system of Ayurveda and Homeopathy have also gained popularity in the state, even though the state has invested over $80 \%$ of its health expenditure in modern medicine. The Ayurveda practitioners and homeopaths work more in the villages and in the private sector. The net result of all this is the diffusion of health care facilities in the state. It was estimated that in 1987 the average area served by a modern medical centre in the rural areas of the state was $9.8 \mathrm{~km}^{2}$ compared with 0.8 $\mathrm{km}^{2}$ in urban areas. If all the systems were considered, the area falls to $5 \cdot 0 \mathrm{~km}^{2}$ in the rural areas compared with $0.5 \mathrm{~km}^{2}$ in urban areas. Needless to say that the excellent network of roads in the state and phenomenal growth of transportation facilities have contributed greatly to the utilization of health care facilities. Every village in Kerala has a bus stop within $2 \mathrm{~km}$, and has access to a few taxis for hire.

It is often suggested that the improved health status of Kerala is also the result of Kerala's egalitarian policies dating back to the last century. This is particularly true of the Travancore-Cochin region where the former rulers pursued progressive health policies which were continued by the democratically elected governments after independence. As supporting evidence, the relatively poor state of health of the former Malabar region at the time of formation of the united Kerala state is cited (Krishnan, 1991). While this is true to some extent, that does not appear to be the principal reason.

What is most interesting are the observations on the nutritional status of the people. All food intake studies which suggest very low intake in the state have often raised questioning eyebrows. While one may dispute the precision of the actual values recorded, there can be no doubt that the people in Kerala are among those who consume the lowest amount of food in the country. The NNMB observations have been independently corroborated by other food intake studies (National Sample Survey Organization, 1983). The question one asks, therefore, is how could such low levels of intake coexist with growth performance matching that of many states, where the food intake is not only better, but more than the recommended intake? The only possible explanation is that the nutrients are better utilized, quite possibly because of the positive interaction between health care and nutrition. We have already discussed that utilization of health care in the state is quite excellent. In fact the use of antenatal care in the state is so good that $92 \%$ of the births now take place in institutions and the consumption of Fe-folic acid tablets for the correction of anaemia is nearly complete (United Nations Children's Fund, 1991b). The maternal perceptions of health care are excellent and breast feeding is nearly always practised at least for the first 6 months (Malathy Damodaran, 1991). The babies, therefore, get a good start in life and subsequent care of the children is also excellent. In fact the proportion of women and children attending the governmental health care system constitutes nearly $69 \%$, much in excess of their share of the population. One, therefore, is tempted to postulate that prompt medical care and the consequent reduction in the days of morbidity may enable the child to better utilize the nutrients it consumes. Prompt medical attention also prevents the widespread occur- 
rence of the more florid forms of nutritional disorders, a fact well-recognized in Kerala. It should be noted that in Kerala the intake of all micronutrients, except calcium, is lower than the recommended levels.

The predominant form of malnutrition in Kerala is growth retardation. Stunting is the dominant form, although wasting is also observed in significant numbers of children. The nutritional picture is not much different from the rest of the country, except for a small decrease in the number of severely malnourished children and an increase in the number of normal children. Nearly $80 \%$ of children suffer from mild to moderate malnutrition, not much different from the situation in other states.

One should consider whether nutritional supplementation has played any role in determining the overall nutritional status of the children in the state. Like all other Indian states, Kerala has also not been lacking in populist policies, with strong emphasis on child feeding. Feeding programmes aimed at the very young cover an estimated $30 \%$ of the target population and school lunches are provided for $80 \%$ of primary schoolchildren. Independent evaluations of the feeding programmes have revealed that they have failed to achieve the nutritional objectives (Soman \& Soman, 1976). Even the impact of the Integrated Child Development Services (ICDS) programme which covers over $40 \%$ of the population is considered marginal. All-India studies on ICDS villages and control villages indicate that the programme has brought about a small reduction in the prevalence of severe malnutrition (a $2 \%$ difference between control and test villages) and a modest increase of $5 \%$ of normal and mildly malnourished children (United Nations Children's Fund, 1991a).

What Kerala demonstrates is that populations with low food intake can still achieve considerably improved health levels characterized by sharp reductions in child mortality. Perhaps one should also conclude that mortality reduction is not the only achievement, since enrolment in schools is nearly $100 \%$ in the age-group 6-14 years and school drop-out rates are the lowest in the country. Low food intake notwithstanding, this indicates a quality of life commendable by the standards of the Third World countries. But one should concede that the state of health is rather fragile, in view of the high levels of reported sickness. While maternal education has brought about proper attitudes and health behaviour, the price people pay is the excessive dependence on the health care system where poor people are spending as much as $14 \%$ of their income on health care (Kannan et al. 1991). Greater emphasis on income generation activities and better coverage with protected water and sanitation programmes could bring about dramatic changes in the field of health and nutrition. The combination of better nutrient intake and improved environment is certain to bring about improved nutritional status and accelerate the positive secular trend in growth observed in recent times.

\section{REFERENCES}

Caldwell, J. C. (1986). Routes to low mortality in poor countries. Population and Development Review 12, $171-220$.

Census of India (1991). Preliminary Tables - Kerala, 1991. New Dehli: Government of India.

Government of Kerala (1991). Economic Review - 1990. Trivandrum: State Planning Board.

Institute of Management in Government (1989). Situation Analysis of Children and Women in Kerala. Trivandrum: Government of Kerala.

Kannan, K. P., Thankappan, K. R., Ramankutty, V. \& Aravindan, K. P. (1991). Health Status in Rural Kerala. Trivandrum: Kerala Sastra Sahithya Parishad. 
Krishnan, T. N. (1991). Kerala's Health Transition - Facts and Factors. Working Paper. Trivandrum: Centre for Development Studies.

Lulu Netto (1989). Determinants of birth weight in Kerala. MD Thesis, University of Kerala.

Malathy Damodaran (1991). Infant Feeding and Child Rearing Practices in Two Urban Communities in Kerala. Report Presented to the State Committee on Science, Technology and Environment. Trivandrum: Government of Kerala.

Mari Bhat, P. N. \& Irudaya Rajan, S. (1990). Demographic transition in Kerala revisited. Economic and Political Weekly 25, 1957-1980.

Nag, M. (1983). Impact of social development and economic development on mortality - comparative study of Kerala and West Bengal. Economic and Political Weekly 19, 33-41.

Nair, P. R. G. (1974). Decline in birth rate in Kerala - an explanatory hypothesis about the relationship between demographic variables, health services and education. Economic and Political Weekly 9, 323-326.

National Center for Health Statistics (1976). Growth Charts, HRA 76-1120, vol. 25, p. 3. Rodeville, MD: US Department of Health, Education and Welfare.

National Nutrition Monitoring Bureau (1980). Anmual Report for the Year 1980. Hyderabad: National Institute of Nutrition.

National Nutrition Monitoring Bureau (1990). Report of Nutrition Surveys in Indian States, 1989-1990. Hyderabad: National Institute of Nutrition.

National Sample Survey Organization (1980). Report of the 28th Round - Survey on Morbidity - Sarvekshana, July-October 1980. New Dehli: Government of India.

National Sample Survey Organization (1983). Report of the 35th Round, 1982-1983. New Dehli: Government of India.

Panikar, P. G. K. \& Soman, C. R. (1984). Health Status of Kerala-Paradox of Economic Backwardness and Health Development. Trivandrum, India: Centre for Development Studies.

Ratcliffe, J. (1978). Social justice and demographic transition lessons from India's Kerala state. International Journal of Health Services 8, 123-144.

Soman, C. R. \& Soman, K. R. (1976). A Study on the Impact of School Lunches on the Nutritional Status of School Children of Kerala. Trivandrum: CARE.

United Nations Children's Fund (1991a). Situation Analysis of Children and Women in Kerala. New Dehli: UNICEF.

United Nations Children's Fund (1991b). Children and Women in India. A Situation Analysis 1990. New Dehli: UNICEF

Zacharia, K. C. (1984). The Anomaly of the Fertility Decline in India's Kerala State: a Field Investigation. Staff Working Paper no. 700. The World Bank: Washington DC. 